\title{
Resistance to Phialophora gregata Is Expressed in the Stems of Resistant Soybeans
}

\author{
G. M. Tabor and G. L. Tylka, Department of Plant Pathology, S. C. Cianzio, Department of Agronomy, and \\ C. R. Bronson, Department of Plant Pathology, Iowa State University, Ames 50011
}

\begin{abstract}
Tabor, G. M., Tylka, G. L., Cianzio, S. C., and Bronson, C. R. 2003. Resistance to Phialophora gregata is expressed in the stems of resistant soybeans. Plant Dis. 87:970-976.

Growth chamber experiments were conducted to determine if resistance to Phialophora gregata, the causal agent of brown stem rot (BSR) of soybean, is expressed in the stems of resistant soybean genotypes. Upon introduction of the pathogen into the base of stems of 2-week-old seedlings, the fungus advanced with the growing tips of plants of susceptible genotypes but lagged behind in resistant genotypes. Five weeks after introduction of the pathogen, both mean percent stem length colonized by $P$. gregata and mean percentage of symptomatic trifoliate leaflets were significantly less for resistant than for susceptible genotypes. These results indicate that resistance can be expressed in the stems of resistant soybean plants and suggest that stem inoculation methods may be useful for assessing resistance to P. gregata. Also, in our experiments, internal stem discoloration was not as useful as colonization and foliar symptoms in discriminating resistant from susceptible genotypes.
\end{abstract}

Additional keywords: BSR, disease resistance

Brown stem rot (BSR) of soybean (Glycine $\max$ (L.) Merr.), caused by the vascular pathogen Phialophora gregata (Allington \& D. W. Chamberlain) W. Gams (1), is an economically important disease of soybean in the north-central United States. BSR is prevalent in 68 to $73 \%$ of the soybean fields of Illinois, Iowa, and Minnesota (18). The currently recommended BSR management strategy is use of BSRresistant soybean cultivars combined with rotation to nonhost crops (19).

Selection of BSR-resistant cultivars in breeding relies heavily on artificial inoculation methods; however, there is uncertainty in the literature about which organs of the soybean plant actually express resistance: roots, stems, or both. This uncertainty has hampered the choice and development of appropriate $P$. gregata inoculation methods and resistance assays. Some research suggests that BSR resistance is limited to the roots, whereas other research suggests it also is expressed in the stems. For example, Phillips (13) reported that PI 84946-2, the source of BSR resistance for most commercial cultivars, developed severe BSR symptoms when inoculated in the stem with $P$. gregata, which could be interpreted as indicating that resistance is not expressed in the stems. Bachman and Nickell (2) attempted to

Corresponding author: G. M. Tabor

E-mail: gtabor@iastate.edu

Accepted for publication 31 March 2003.

Publication no. D-2003-0523-01R

(c) 2003 The American Phytopathological Society specifically test the location of BSR resistance by inoculating the roots of reciprocal grafts of BSR-susceptible and -resistant soybean genotypes. They reported that resistant scions had more severe BSR symptoms when grafted on susceptible rootstocks than when grafted on resistant rootstocks. Therefore, they concluded that BSR resistance is "root-limited." This conclusion, however, is not consistent with the results of Lewers et al. (9), who detected quantitative trait loci (QTL) associated with $P$. gregata resistance when $P$. gregata was directly introduced into the stems. The main QTL detected using this inoculation technique was the same QTL that was detected when these soybean lines were planted in $P$. gregata-infested fields (9).

The expression of BSR resistance in soybean roots does not seem to be in dispute. The published data, however, are contradictory as to whether resistance also is expressed in the stems. The specific objective of the research reported herein was to determine whether BSR resistance is expressed in the stems of resistant soybean genotypes.

\section{MATERIALS AND METHODS}

Three experiments, each conducted twice (1A, 1B, 2A, 2B, 3A, and 3B), assessed the expression of BSR resistance in the stems of BSR-resistant soybean genotypes. Experiments 1A, 1B, 3A, and 3B also determined the reliability of internal stem discoloration in distinguishing resistant from susceptible genotypes when $P$. gregata was introduced directly into the stems. Experiments 4A and 4B assessed the reliability of stem colonization for differentiating resistant from susceptible soybean genotypes when plants were inoculated with $P$. gregata without wounding the stems.

Soybean genotypes. The soybean genotypes tested in experiments $1 \mathrm{~A}, 1 \mathrm{~B}, 4 \mathrm{~A}$, and $4 \mathrm{~B}$ were the BSR-resistant BSR101 (16) and the BSR-susceptible Sturdy (12). In experiments $2 \mathrm{~A}$ and $2 \mathrm{~B}$, eight genotypes (three susceptible and five resistant) were tested. In experiments $3 \mathrm{~A}$ and $3 \mathrm{~B}, 17$ genotypes (11 resistant and 6 susceptible) were tested. These genotypes either are the original sources of BSR resistance used in most commercial genotypes or have been reported as BSR resistant or BSR susceptible (Table 1).

Seed of each genotype were planted either in an autoclaved mix of sand and soil (1:1; experiments $1 \mathrm{~A}, 1 \mathrm{~B}, 4 \mathrm{~A}$, and $4 \mathrm{~B})$ or in a pasteurized mix of soil, sand, and perlite $(2: 1: 2$; experiments $2 \mathrm{~A}, 2 \mathrm{~B}, 3 \mathrm{~A}$, and $3 \mathrm{~B}$ ) in 4-by-21-cm plastic, coneshaped containers (Stuewe and Sons, Corvallis, OR). There was one plant per container, and plants were grown in a growth chamber set at a constant temperature of $22^{\circ} \mathrm{C}$; actual mean temperatures ranged from 20 to $24^{\circ} \mathrm{C}$ depending on the experiment. In all experiments, plants were grown under $16 \mathrm{~h}$ of light and were fertilized weekly.

Inoculation or infestation. The $P$. gregata strain (OH2-3) used in the study (9) was a single-spore isolate of strain $\mathrm{Oh}_{2}$ (6) provided by Cecil Nickell at the University of Illinois. Cultures were started on green bean extract (GBE) medium (ground frozen Phaseolus vulgaris L. green pods at 35 $\mathrm{g} /$ liter and agar at $20 \mathrm{~g} / \mathrm{liter}$ ) supplemented with ampicillin at $50 \mathrm{mg} / \mathrm{liter}$ and were incubated for 44 to 64 days at room temperature $\left(21\right.$ to $\left.23^{\circ} \mathrm{C}\right)$ in the dark until abundant sporulation was evident.

In experiments $1 \mathrm{~A}, 1 \mathrm{~B}, 2 \mathrm{~A}, 2 \mathrm{~B}, 3 \mathrm{~A}$, and $3 \mathrm{~B}$, Phialophora gregata inoculum was introduced in the stem. Conidia of $P$. gregata were suspended in $0.8 \%$ water agar $\left(2.7 \times 10^{7}\right.$ conidia/ml in experiments $1 \mathrm{~A}$, $1 \mathrm{~B}, 2 \mathrm{~A}$, and $2 \mathrm{~B}$ and $1.8 \times 10^{7}$ conidia $/ \mathrm{ml}$ in experiments $3 \mathrm{~A}$ and $3 \mathrm{~B}$ ). The conidial suspension was mixed thoroughly into a paste. Stems of 2-week-old plants were punctured approximately $2 \mathrm{~cm}$ above the soil line with an 18-gauge needle (Becton Dickinson, Franklin Lakes, NJ) with its bevel filled with the inoculum paste. A needle with water agar paste without conidia was stabbed into stems of control plants.

In experiments $4 \mathrm{~A}$ and $4 \mathrm{~B}, P$. gregata inoculum was applied to the soil around 
the base of plants without wounding. In experiment $4 \mathrm{~A}$, the population density of conidia was adjusted to $3.3 \times 10^{6}$ conidia/ml of sterile deionized water; $3 \mathrm{ml}$ of this suspension $\left(10^{7}\right.$ conidia) was applied to the soil surface around the base of 2week-old plants. In experiment $4 \mathrm{~B}$, the population density of conidia was $1 \times 10^{7}$ conidia/ml of sterile deionized water, and 1 $\mathrm{ml}$ of this suspension was applied to the soil around the base of 2-week-old plants. Uninoculated plants of both genotypes were included as controls in both experiments.

Experimental design. In all experiments, plants were arranged in a randomized complete block design; blocks were locations in the growth chamber. There were five blocks in experiment $1 \mathrm{~A}$ and three in experiment $1 \mathrm{~B}$, and each treatment combination (one plant) occurred once in each block. In experiments $2 \mathrm{~A}$ and $2 \mathrm{~B}$, there were four blocks and each treatment combination (one plant) occurred once in each block. There were 10 blocks in experiment $3 \mathrm{~A}$ and 9 blocks in experiment $3 \mathrm{~B}$ and each treatment combination (one plant) occurred once in each block. In experiments $4 \mathrm{~A}$ and $4 \mathrm{~B}$, there were four blocks, and each treatment combination occurred once in each block. Each treatment combination comprised two (4A) or three (4B) plants (containers) in a row.

Incidence and severity assays. Incidence and severity of BSR symptoms and $P$. gregata colonization were assessed weekly over a 5-week period in experiments $1 \mathrm{~A}, 1 \mathrm{~B}, 2 \mathrm{~A}$, and $2 \mathrm{~B}$; once 5 weeks after inoculation in experiments $3 \mathrm{~A}$ and $3 \mathrm{~B}$; and every 1 to 2 weeks over a 12 -week period in experiments $4 \mathrm{~A}$ and $4 \mathrm{~B}$.

To determine the extent of $P$. gregata colonization and internal stem discoloration, stems were cut at the soil line and immersed for $3 \mathrm{~min}$ in $70 \%$ ethanol, followed by $5 \mathrm{~min}$ in $10 \%$ sodium hypochlorite (Clorox) and a final rinse in sterile, deionized water. Stem length was measured and the stems were cut into 2-cm-long pieces. In experiments in which both discoloration and colonization data were collected, the stem pieces were split in half lengthwise and discoloration was assessed prior to plating of the stem pieces. Incidence of internal stem discoloration was assessed visually. A plant was considered discolored if there was any visible dark brown discoloration on the vascular tissue or the pith on any of the stem pieces. Severity of discoloration (percent stem length discolored) was calculated by adding the discolored lengths of the individual stem pieces. Because collection of discoloration data was subjective, a single investigator collected all discoloration data within a block without knowledge of the treatments.

To determine the percentage of stems colonized (incidence) and maximum height of colonization, one-half of each split stem piece was plated on GBE agar supplemented with ampicillin. In experiments $2 \mathrm{~A}$ and $2 \mathrm{~B}$, the 2-cm-long stem pieces were not split before plating. The relative position of each stem piece on the plant was recorded, and plates were incubated at $15^{\circ} \mathrm{C}$ in the dark for 15 days. The emerging fungal mycelia were examined for characteristic $P$. gregata conidia and conidiophore morphology under a microscope. A stem (plant) was considered colonized if $P$. gregata was recovered from any portion of any stem piece. In all instances, stems were colonized starting from the base up to the maximum height colonized without gaps. Severity of colonization was calculated by dividing the maximum height colonized by the total stem height. Colonization data were collected without knowledge of the treatments.

Foliar symptoms were assessed as the proportion of symptomatic trifoliate leaflets. Each trifoliate was recorded as healthy, chlorotic, stunted, necrotic, or abscised. If a leaflet was normal in size, not deformed, and not necrotic, it was recorded as healthy or chlorotic depending on the predominant $(>50 \%)$ color of the leaflet. If a leaflet was abnormally small and deformed but not necrotic, it was recorded as stunted. If there was any necrotic area in the leaf, it was recorded as necrotic, and if the leaflet had fallen off the plant it was recorded as abscised (missing). Severity of foliar symptoms was determined using the formula: (stunted trifoliate leaflets + necrotic trifoliate leaflets + abscised trifoliate leaflets/ total trifoliate leaflets) $\times 100 \%$. Chlorotic leaflets were not included in calculations of symptom severity because many of the noninoculated plants had chlorotic leaflets. Foliar symptoms were assessed without knowledge of the treatments.

Data analyses. All statistical analyses were conducted using the SAS software

Table 1. Soybean genotypes used in experiments ${ }^{\mathrm{a}}$

\begin{tabular}{|c|c|c|c|}
\hline Genotype & Experiment no. & $\begin{array}{l}\text { Proposed BSR } \\
\text { resistance gene }\end{array}$ & Reference or source \\
\hline A95-581022 & 2,3 & None & ISU \\
\hline Corsoy 79 & 2,3 & None & 4 \\
\hline P9233 & 2,3 & None & Pioneer Hi-Bred Intl. Inc. \\
\hline Parker & 3 & None & 12 \\
\hline Sturdy & $1,3,4$ & None & 11 \\
\hline PI84946-2 & 3 & $R b s 1$ and/or $R b s 3$ & 7,15 \\
\hline A95-682026 b & 2,3 & $R b s 1$ and/or $R b s 3$ & ISU \\
\hline A96-597011 ${ }^{\mathrm{b}}$ & 2,3 & $R b s 1$ and/or $R b s 3$ & ISU \\
\hline Archer ${ }^{b}$ & 3 & $R b s 1$ and/or $R b s 3$ & 5 \\
\hline BSR101 & $1,2,3,4$ & $R b s 1$ and/or $R b s 3$ & 16 \\
\hline IA1006 ${ }^{\mathrm{b}}$ & 3 & $R b s 1$ and/or $R b s 3$ & ISU \\
\hline IA $2008 R^{b}$ & 3 & $R b s 1$ and/or $R b s 3$ & ISU \\
\hline IA $2050^{\mathrm{b}}$ & 3 & $R b s 1$ and/or $R b s 3$ & ISU \\
\hline IA3010 & 3 & None & ISU \\
\hline PI 437833 & 3 & $R b s 2$ & 7 \\
\hline PI 437970 & 2,3 & Rbs 3 & 17 \\
\hline $\mathrm{Jack}^{\mathrm{c}}$ & 2,3 & Unknown & 10 \\
\hline
\end{tabular}

${ }^{\mathrm{a}} \mathrm{BSR}=$ brown stem rot; ISU = experimental genotypes obtained from Department of Agronomy, Iowa State University, Ames.

${ }^{\mathrm{b}}$ Genotypes with resistance derived from BSR101 or PI 84946-2.

${ }^{c}$ BSR resistance derived from unknown source. Inc., Cary, NC). Stem length, stem length colonized, stem length discolored, and percentage of symptomatic trifoliate leaflets data were analyzed using the GLM procedure. Data were pooled for experiments $1 \mathrm{~A}$ and $1 \mathrm{~B}$ because experimenttreatment interaction was not significant $(P$ $>0.05)$. Similar pooling was done for experiments $2 \mathrm{~A}$ and $2 \mathrm{~B}$. Data on incidence of $P$. gregata colonization and discoloration over time from experiments $4 \mathrm{~A}$ and $4 \mathrm{~B}$ were analyzed by logistic regression (8) using the GENMOD procedure; $\chi^{2}$ analysis was used to test the difference between soybean genotypes.

\section{RESULTS}

In experiments $1 \mathrm{~A}$ and $1 \mathrm{~B}, P$. gregata was isolated from all $P$. gregata-inoculated fungus was isolated from all heights (base to apex) of the stems of both susceptible Sturdy and resistant BSR101 at the first sampling time, 1 week after inoculum was introduced directly into the stems. In succeeding weeks, the pathogen advanced with the growing tip more readily $(P<$ $0.0001)$ in Sturdy than in BSR 101. There was no significant difference $(P=0.38)$ in plant height between Sturdy and BSR101 plants. Therefore, the difference in colonization of the pathogen in the stems of the two genotypes was not attributable to a difference in the rate of plant growth between the two genotypes. There was no significant difference $(P=0.96)$ in severity of internal discoloration over 5 weeks between susceptible Sturdy and resistant BSR101.

$P$. gregata was isolated from 97.5 and 99.4\% percent of $P$. gregata-inoculated plants in experiments $2 \mathrm{~A}$ and $2 \mathrm{~B}$, respectively. In both experiments, the fungus was isolated from all heights (base to apex) of package (version 7.0 or 8.2 ; SAS Institute plants at all sampling times (Fig. 1). The 
the infected stems of both susceptible and resistant genotypes at the first sampling time, 1 week after inoculum was introduced directly into the stems (Fig. 2). However, in succeeding weeks, the pathogen advanced with the growing tip more readily $(P<0.0001)$ in susceptible than in resistant genotypes. There was a difference $(P<0.001)$ in plant height between resistant and susceptible genotypes. However, this height difference was not responsible for the difference in stem length colonized between resistant and susceptible genotypes. When stem length colonized data were converted into percent stem length colonized (stem length colonized/total stem length $\times 100 \%$ ) and analyzed using the GLM procedure, susceptible genotypes had greater $(P<0.0001)$ percent stem length colonized by the fungus than resistant cultivars. Therefore, the difference in colonization of the pathogen in the stems of susceptible and resistant genotypes was not attributable to the difference in rate of plant growth between susceptible and resistant soybeans.

In experiments $3 \mathrm{~A}$ and $3 \mathrm{~B}$, data were collected from a wider range of soybean genotypes than in experiments $2 \mathrm{~A}$ and $2 \mathrm{~B}$; plants were sampled 5 weeks after introduction of the pathogen rather than weekly. $P$. gregata was isolated from 99.4 and $98.8 \%$ percent of $P$. gregata-inoculated plants in experiments $3 \mathrm{~A}$ and $3 \mathrm{~B}$, respectively. In both experiments $3 \mathrm{~A}$ and $3 \mathrm{~B}$, mean percent stem length colonized by $P$. gregata for the susceptible genotypes was significantly $(P<0.0001)$ greater than the mean for the resistant genotypes (Fig. $3 \mathrm{~A}$ and $\mathrm{D}$ ). Likewise, mean percentages of symptomatic trifoliate leaflets for the susceptible genotypes were significantly $(P<$ $0.0001)$ greater than the mean for the resistant genotypes in both experiments (Fig. $3 \mathrm{C}$ and $\mathrm{F})$. There was no difference $(P=$ 0.0867) in internal stem discoloration between resistant and susceptible soybean genotypes in experiment 3A (Fig. 3B), and resistant genotypes had significantly $(P=$ $0.0005)$ greater discoloration than susceptible genotypes in experiment 3B (Fig. 3E).

To determine whether the reduced colonization of stems of resistant cultivars by $P$. gregata was an artifact of stem inoculation, experiments 4A and 4B were conducted using an inoculation method that did not wound the stem. Specifically, inoculum was applied to the soil around the base of 2-week-old seedlings. The colonization data from experiments $4 \mathrm{~A}$ and $4 \mathrm{~B}$ (Fig. 4) were consistent with experiments that used direct stem inoculation. In both experiments, colonization distinguished the resistance and susceptibility of BSR101 and Sturdy. Sturdy and BSR101 differed in incidence (experiment 4A, $P=0.057$; experiment $4 \mathrm{~B}, P<0.0001)$ and severity

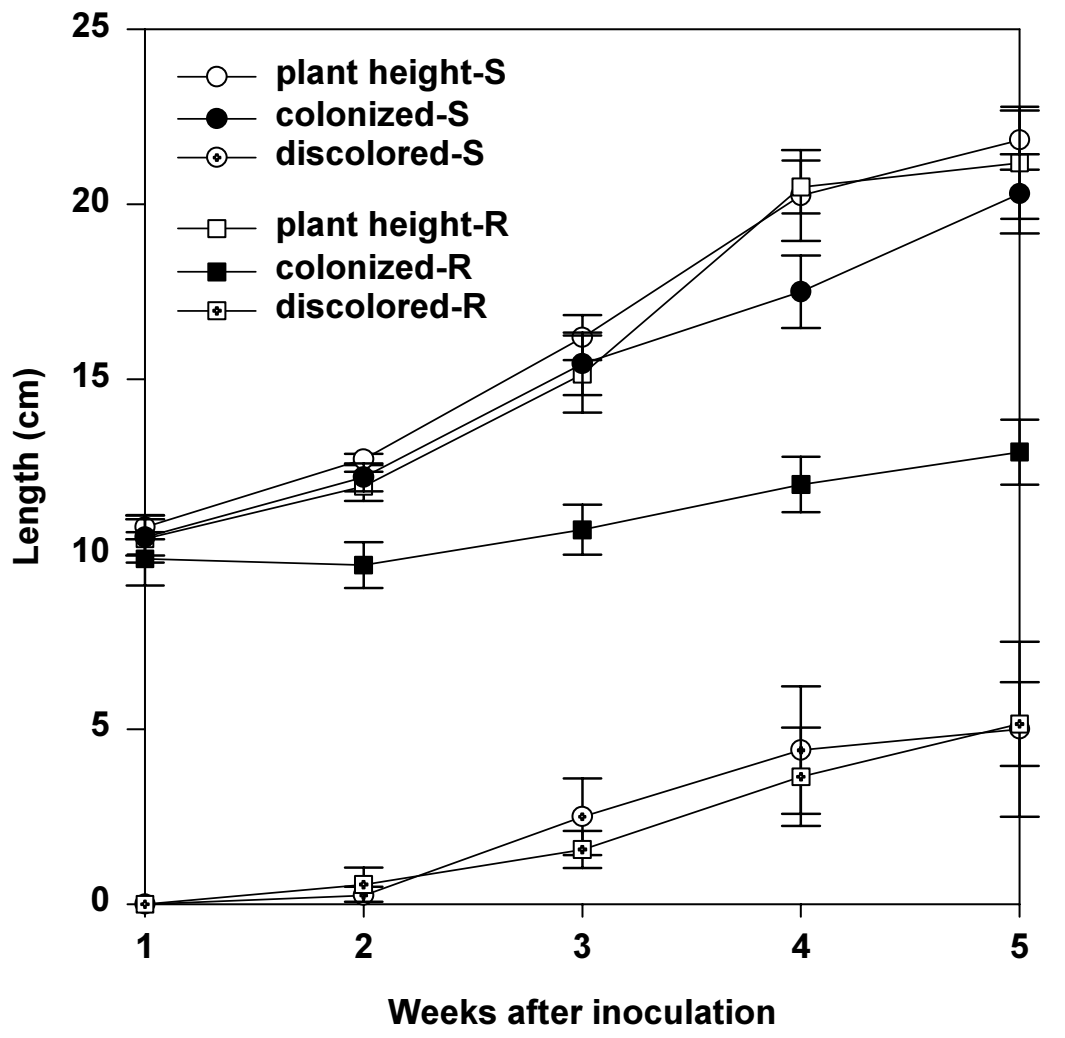

Fig. 1. Stem colonization and internal stem discoloration after introduction of conidia of Phialophora gregata into the base of stems of 2-week-old plants of susceptible (S) Sturdy and resistant (R) BSR101 soybean. Each data point represents the combined mean of a total of eight replicates from two experiments (1A and $1 \mathrm{~B})$. Each error bar represents the standard error for each week and for each soybean cultivar. (experiment 4A, $P=0.0225$; experiment $4 \mathrm{~B}, P<0.0001)$ of $P$. gregata colonization over time. Incidence and severity of internal stem discoloration was low for both Sturdy and BSR101 in both experiments even at 12 weeks after inoculation. There was greater variation within treatments, as shown by error bars, for severity of colonization in experiments $4 \mathrm{~A}$ and $4 \mathrm{~B}$, in which $P$. gregata spores were applied to the soil, than in experiments $1 \mathrm{~A}, 1 \mathrm{~B}, 2 \mathrm{~A}, 2 \mathrm{~B}, 3 \mathrm{~A}$, and $3 \mathrm{~B}$, in which inoculum was introduced directly into the stem.

\section{DISCUSSION}

Our results indicate that resistance to $P$. gregata colonization and to BSR foliar symptoms is expressed in the stems of BSR-resistant soybean genotypes. There was reduced $P$. gregata colonization of stems and reduced foliar symptom expression in a wide range of BSR-resistant genotypes, including PI 84946-2 (Rbs1), PI 437833 (Rbs2), PI 437970 (Rbs3), and Jack (unknown gene or genes) when inoculum was introduced directly into the stems. Our results are consistent with those of Lewers et al. (9), who detected QTL controlling BSR resistance using the same stem inoculation technique used in our experiments. Thus, our results and those of Lewers et al. suggest that BSR resistance is expressed in the stems of BSR-resistant soybean genotypes and that stem inoculation methods may be useful in BSR research.

Our results do not support the earlier report by Bachman and Nickell (2) that BSR resistance is root-limited. Bachman and Nickell inoculated the roots of reciprocal grafts of susceptible and resistant genotypes with $P$. gregata and demonstrated that grafts with resistant rootstocks had less severe BSR symptoms than grafts with susceptible rootstocks. Therefore, they concluded that BSR resistance is present in the roots, and that, in addition, it is rootlimited in all the BSR-resistance sources they evaluated. In contrast, when we bypassed the roots and inoculated the stems with $P$. gregata, we detected reduced colonization of stems by $P$. gregata and reduced foliar symptoms in a wide range of BSR-resistant genotypes, indicating that resistance also is expressed in the stems of BSR-resistant soybean plants.

There is a possible explanation why Bachman and Nickell were unable to detect BSR resistance in the stem using reciprocal grafts and root inoculation, whereas we were able to detect it using stem inoculation. If a resistant scion is grafted on a susceptible rootstock and the rootstock is inoculated with $P$. gregata, secondary inoculum abundantly produced on the susceptible rootstock could continuously move up to the resistant scion and possibly overwhelm any resistance present in the scion. Our results are consistent with such a hypothesis. In our experiments, the 

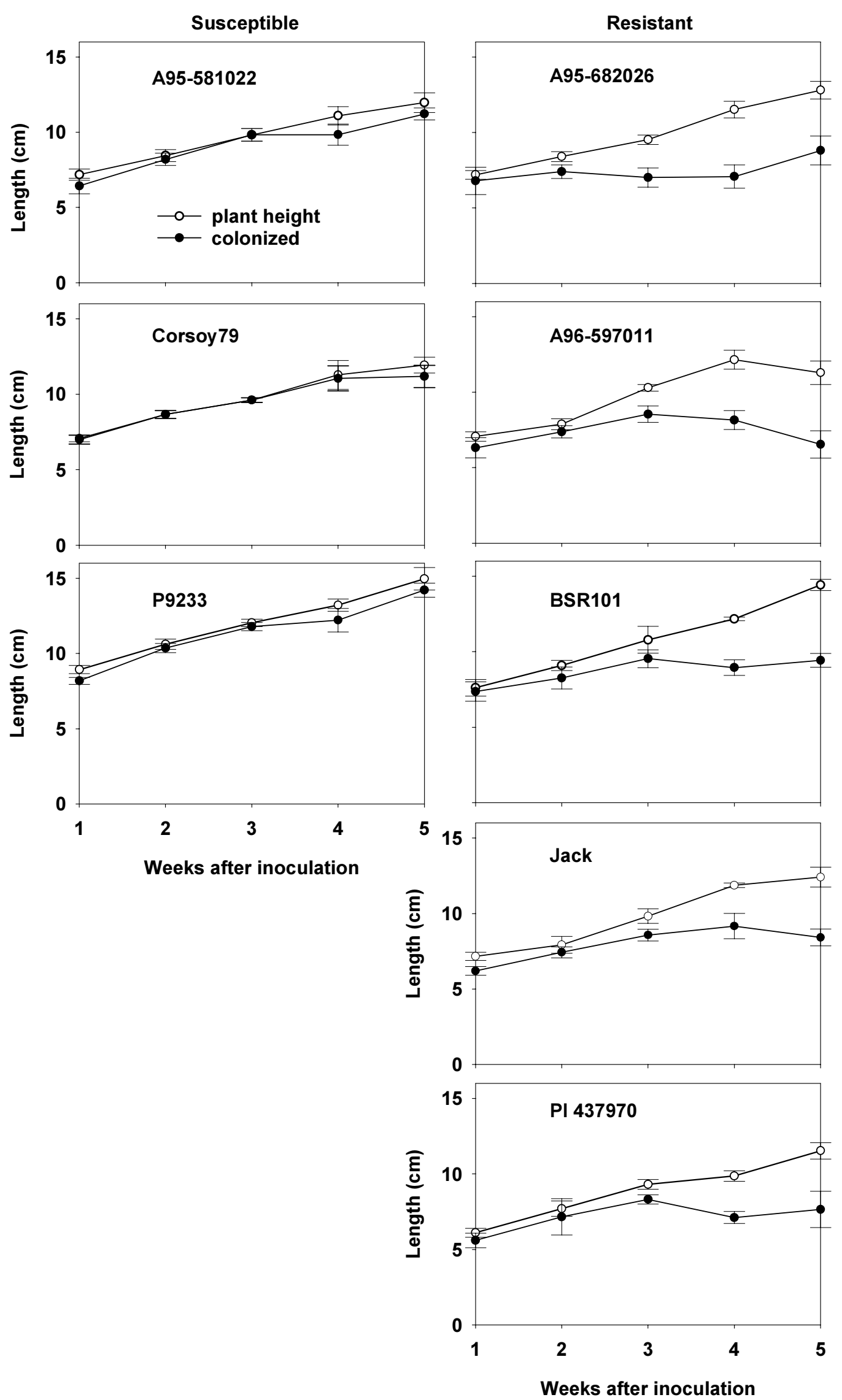

Fig. 2. Severity of stem colonization after introduction of conidia of Phialophora gregata into the base of stems of 2-week-old plants of three susceptible and five resistant soybean genotypes. Results presented are for combined experiments $2 \mathrm{~A}$ and $2 \mathrm{~B}$. Each data point represents the mean of eight replicates with one plant each. Each error bar represents standard error for each week and for each soybean genotype. 
fungus was isolated from base to apex of both resistant and susceptible genotypes 1 week after inoculum was introduced at the base of the stems (Figs. 1 and 2). This fast advance of the fungus following inocula- tion of the stem suggests that conidia of $P$. gregata can move readily through the xylem vessels of both BSR-resistant and BSR-susceptible soybean. Our results and previous reports $(7,14,17)$ indicate that
BSR-resistant cultivars generally exhibit some BSR symptoms, suggesting that resistance is incomplete. In addition, our results indicate that the fungus can colonize both resistant and susceptible cultivars
Experiment 3A
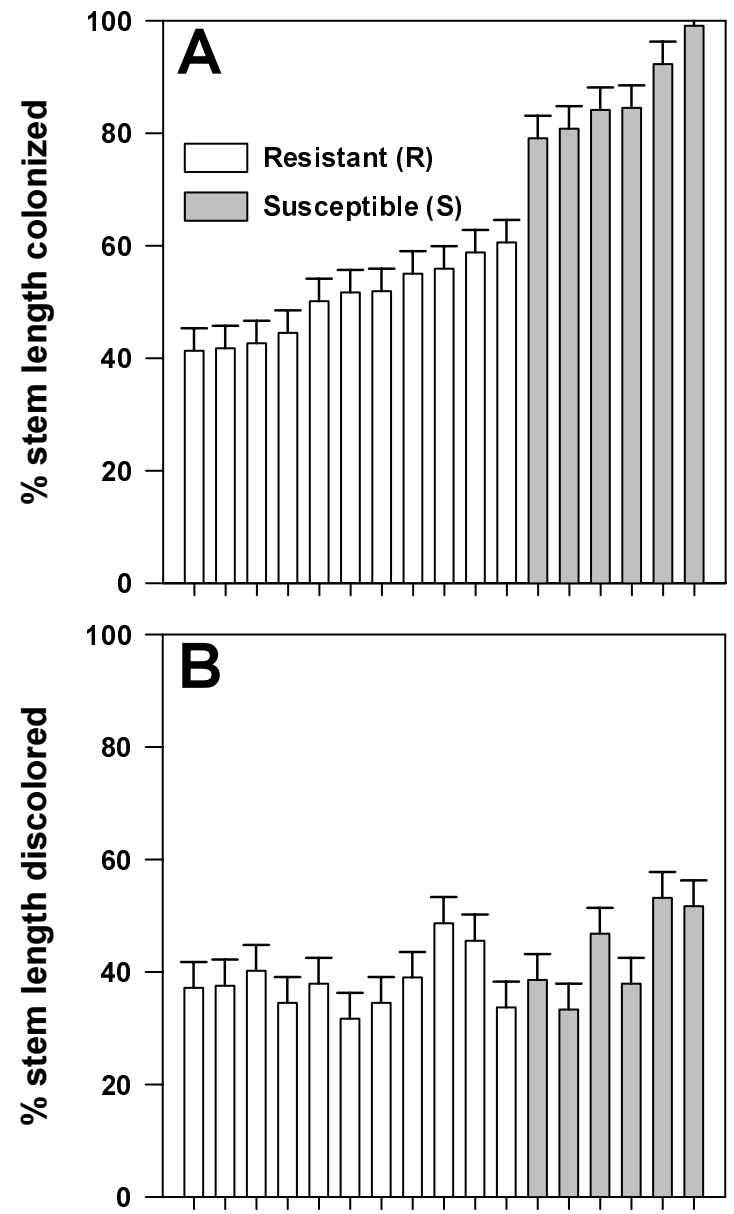

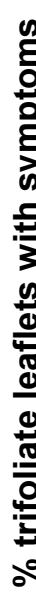

100

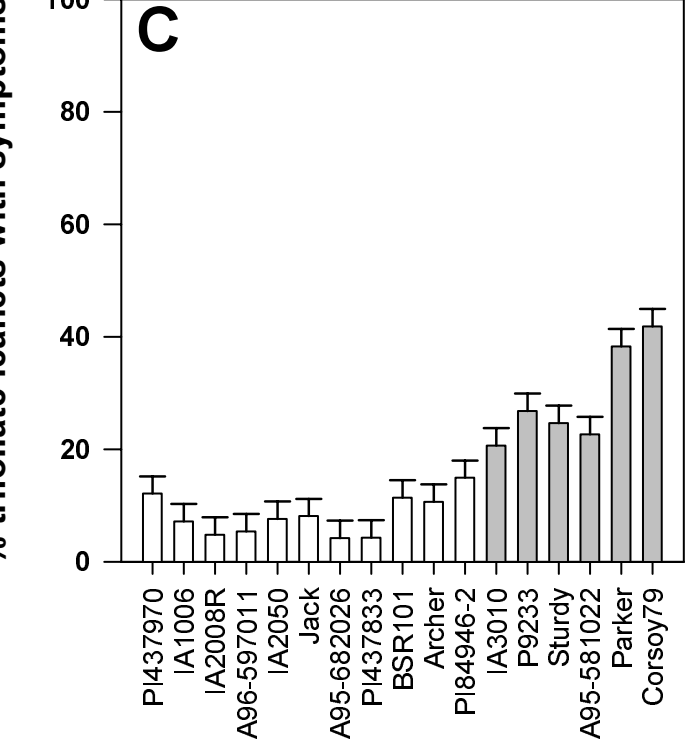

Soybean cultivars

Fig. 3. Severity of stem colonization, stem symptoms, and foliar symptoms 5 weeks after conidia of Phialophora gregata were introduced into the base of the stems of 2-week-old resistant and susceptible soybean genotypes. Results presented are for experiments $3 \mathrm{~A}$ and $3 \mathrm{~B}$. Values are means of 10 replicates in experiment 3A and 9 replicates in experiment $3 \mathrm{~B}$ with one plant each. Error bars represent experiment-wise standard error. 
even when inoculum is applied to the soil around the base of plants. Thus, it would not be surprising if BSR-resistant scions grafted on BSR-susceptible rootstocks were overwhelmed by secondary inoculum produced in the susceptible rootstocks and continually transported to the scions.

Our data also suggest that measurements of stem colonization may be more reliable than measurements of internal stem discoloration for distinguishing resistant from susceptible soybean genotypes. Stem colonization was consistently effective and foliar symptoms were generally effective in discriminating resistant from susceptible genotypes in our experiments; however, internal stem discoloration was ineffective in most experiments. In fact, internal stem discoloration was frequently absent in stems that were heavily colonized by $P$. gregata (Fig. 4). This lack of internal stem discoloration in infected soybean could contribute to the reported difficulty in distinguishing resistant from susceptible genotypes in commonly used screening procedures, which usually rely, at least in part, on measurements of internal stem discoloration $(3,15)$. In our experiments, stem colonization more consistently distinguished resistant from susceptible genotypes than did foliar symptoms (note the low ability of foliar symptoms to distinguish resistant from susceptible genotypes; Fig. 3C). However, it is not known whether this difference between stem colonization and foliar symptoms occurs commonly. The variable effectiveness of foliar symptoms for distinguishing resistant from susceptible soybean genotypes has been noted previously; Sebastian et al (15) reported that the heritability of BSR resistance based on foliar symptoms was 0.0 and 0.38 in two greenhouse experiments.

Our demonstration that resistance is expressed in soybean stems suggests a novel method for assaying BSR resistance that does not depend on assessment of stem or foliar symptoms. When $P$. gregata was introduced into the stem, the pathogen rapidly moved to the stem apices of both susceptible and resistant plants. However, in the subsequent weeks, the pathogen advanced with the growing tip in the susceptible genotypes but lagged behind in the resistant genotypes (Figs. 1, 2, and 3). Such a difference between resistant and susceptible plants has the potential to be
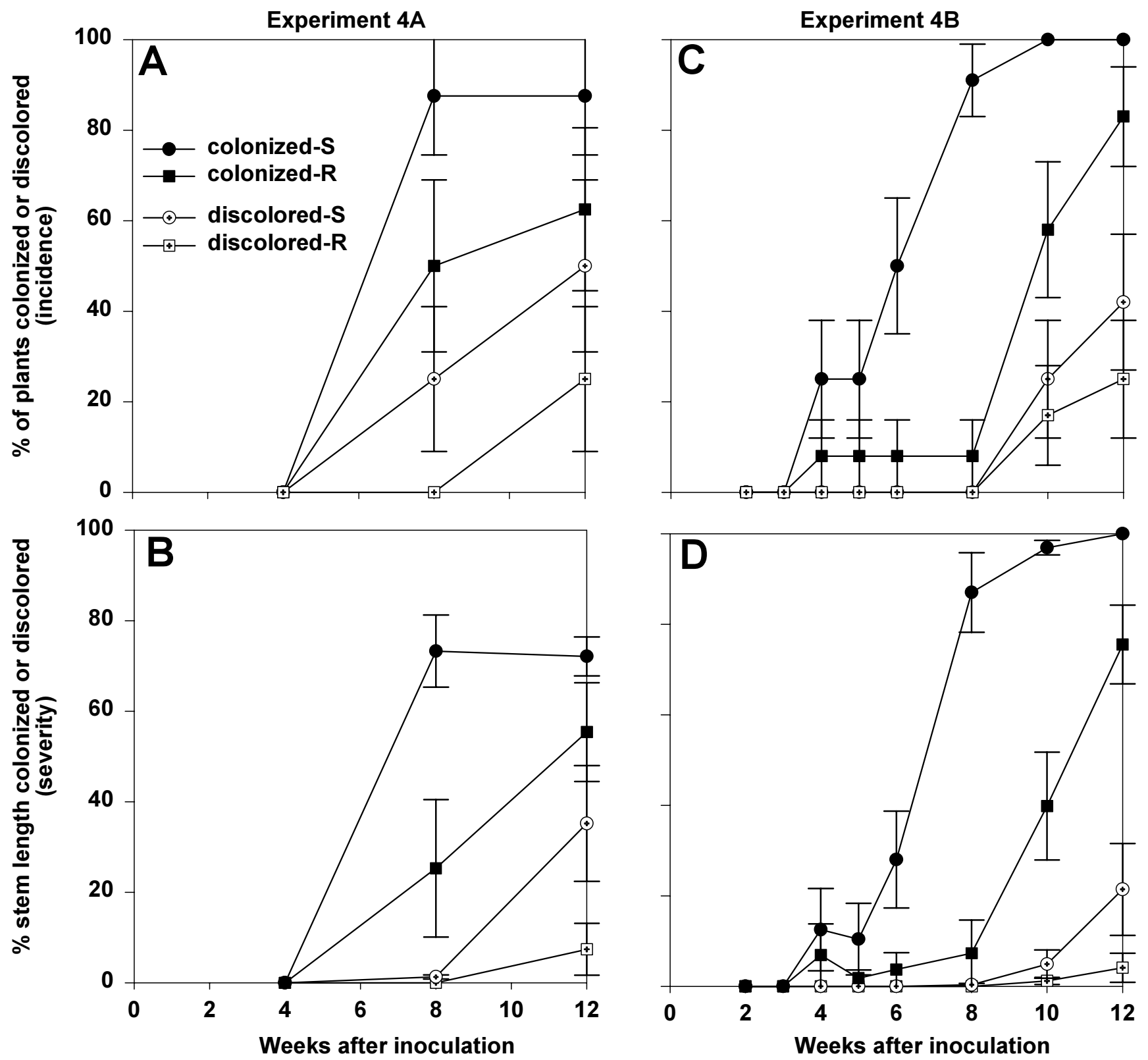

Fig. 4. Incidence and severity of stem colonization and stem discoloration in the stems of susceptible (S) Sturdy and resistant (R) BSR101 soybeans at various times after conidia of Phialophora gregata were applied to the soil around the base of the plants. Each data point represents the percentage incidence or severity for 8 plants in experiment 4A and 12 plants in experiment 4B. Each error bar represents standard error for each week and for each soybean genotype. 
developed into a resistance screening technique based on inoculation of stems followed by assessment of the top sections of the stems for the presence of the pathogen. The potential for such a screening technique warrants further investigation.

The results reported herein have implications for researchers and breeders who need to reliably assay BSR resistance in soybean genotypes. However, in applying any of the results reported here, it is important to note that they are from experiments that employed limited temperature regimes. Further research will be necessary to determine whether the results are similar under other environmental conditions.

\section{ACKNOWLEDGMENTS}

This research was supported by Hatch Act (Project No. 3288) and State of Iowa funds and a grant from the Iowa Soybean Promotion Board. We thank P. Dixon, Department of Statistics, Iowa State University, for assistance in statistical analysis; and our colleagues D. H. Soh, W. Chen, and C. C. Marett for technical assistance.

\section{LITERATURE CITED}

1. Allington, W. B., and Chamberlain, D. W. 1948. Brown stem rot of soybean. Phytopathology 23:793-802.
2. Bachman, M. S., and Nickell, C. D. 1999. Use of reciprocal grafting to study brown stem rot resistance in soybean. Phytopathology 89:5963.

3. Bachman, M. S., and Nickell, C. D. 2000. Investigating the genetic model for brown stem rot resistance in soybean. J. Hered. 91:316-321.

4. Bernard, R. L., and Cremeens, C. R. 1988. Registration of 'Corsoy 79' soybean. Crop Sci. 28:1027.

5. Cianzio, S. R., Shultz, S. P., Fehr, W. R., and Tachibana, H. 1991. Registration of 'Archer' soybean. Crop Sci. 31:1707.

6. Eathington, S. R., Nickell, C. D., and Gray, L. E. 1995. Inheritance of brown stem rot resistance in soybean cultivar BSR101. J. Hered. 86:55-60.

7. Hanson P. M., Nickell, C. D., Gray, L. E., and Sebastian, S. A. 1988. Identification of two dominant genes conditioning brown stem rot resistance in soybean. Crop Sci. 28:41-43.

8. Hosmer, W. D., and Lemeshow, S. 2000. Applied Logistic Regression. 2nd ed. John Wiley \& Sons, Inc., New York.

9. Lewers, K. S., Crane, E. H., Bronson, C. R., Schuup, J. M., Keim, P., and Shoemaker, R. C. 1999. Detection of linked QTL for soybean brown stem rot resistance in 'BSR101' as expressed in a growth chamber experiment. Mol. Breed. 5:33-42.

10. Nickell, C. D., Noel, G. R., Thomas, D. J., and Waller, R. 1990. Registration of 'Jack' soybean. Crop Sci. 30:1365.

11. Orf, J. H., and Kennedy, B. W. 1994. Registration of 'Parker' soybean. Crop Sci. 34:302-303.

12. Orf, J. H., Lambert, J. W., and Kennedy, B. W. 1991. Registration of 'Sturdy' soybean. Crop Sci. 31:486-487.

13. Phillips, D. V. 1971. Influence of air temperature on brown stem rot of soybean. Phytopathology 61:1205-1208.

14. Sebastian, S. A., and Nickell, C. D. 1985. Inheritance of brown stem rot resistance in soybeans. J. Hered. 76:194-198

15. Sebastian, S. A., Nickell, C. D., and Gray, L. E. 1985. Efficient selection for brown stem rot resistance in soybeans under greenhouse screening conditions. Crop Sci. 26:753-757.

16. Tachibana, H., Voss, B. K., and Fehr, W. R. 1987. Registration of 'BSR101' soybean Crop Sci. 27:612.

17. Wilmot, D. B., and Nickell, C. D. 1989. Genetic analysis of brown stem rot resistance in soybean. Crop Sci. 29:672-674.

18. Workneh, F., Tylka, G. L., Yang, X. B., Faghihi, J., and Ferris, J. M. 1999. Regional assessment of soybean brown stem rot, Phytophthora sojae, and Heterodera glycines using area frame sampling: Prevalence and effects of tillage. Phytopathology 89:204 211.

19. Yang, X. B., and Lundeen, P. 1997. Soybean brown stem rot. Iowa State University, Ext. Publ. Pm-890. 